\title{
Aspects Hindering the Development and Survival of Small and Medium-Sized Enterprises in Pakistan: Stability Perspective
}

\author{
Shoaib Ali \\ School of Management, Jiangsu University, Zhenjiang, China. \\ Email:shooaibali6@gmail.com
}

\begin{abstract}
This article explores aspects that hinder the development and survival of small- and medium-sized enterprises (SMEs) in Pakistan. A survey was developed to collect information from $226 \mathrm{SME}$ owners and staff members in selected provinces in Pakistan, and a statistical approach was used. The results of the research indicate that the expected constraints, including lack of management knowledge, corruption, decaying infrastructure, absence of financial funds, and inadequate earnings, hinder SME development and survival in Pakistan. Considering these elements will help legislators, non-governmental organizations (NGOs), shareholders, policymakers, and others to create well-structured policies and plans that will aggressively promote the efficiency and stability of SMEs in Pakistan. The significance of this research derives from the reality that few studies have been conducted on the development and survival of SMEs in Pakistan from a stability perspective.
\end{abstract}

Keywords: Development and survival, Small \& Medium Enterprises (SMEs), Stability, Pakistan. JEL Classification: H12; L32; O01; Q01.

Citation | Shoaib Ali (2021). Aspects Hindering the Development and Survival of Small and Medium Enterprises in Pakistan: Stability Perspective. Asian Journal of Economics and Empirical Research, $8(1): 10-16$.

History:

History:

eceived: 16 November 2020

Revised: 28 December 2020

Accepted: 19 January 2021

Published: 25 February 2021

Licensed: This work is licensed under a Creative Commons

Attribution 3.0 License (oc)

Publisher: Asian Online Journal Publishing Group
Funding: This study received no specific financial support.

Competing Interests: The author declares that there are no conflicts of interest regarding the publication of this paper.

Transparency: The author confirms that the manuscript is an honest, accurate, and transparent account of the study that was reported, that no vital features of the study have been omitted, and that any discrepancies from the features of the study have been omitted
study as planned have been explained.

study as planned have been explained.
Ethical: This study followed all ethical practices during writing.

\section{Contents}

1. Introduction 


\section{Contribution of this paper to the literature}

This study contributes to the existing literature by exploring aspects that hinder the development and survival of small- and medium-sized enterprises (SMEs) in Pakistan from a stability perspective.

\section{Introduction}

Unlike large companies, SMEs, with their constrained financial resources and funds and inadequate management facilities, tend to receive substantially less financing in the development of an economy. However, the significance of SMEs cannot be stressed enough in the economic development of a country (Syed, Ahmadani, Shaikh, \& Shaikh, 2012). SMEs make up almost 90\% of the contribution among all formal sector enterprises. Promoting small-scale industries would assist in achieving many goals and could help reduce the problem of widespread underemployment, particularly in developing economies such as Pakistan.

This issue is expected to worsen with the accumulation of returning laborers from developing countries. When compared with larger industries, SMEs apply more labor-intensive strategies and use a significant source of revenue. They intensively use the readily available development factor by focusing on domestic inputs, as well as increasing government foreign exchange. Saeed (2013) highlighted that SMEs are important users of scarce resources and have stronger relations with other local economic sectors.

Even these inherent characteristics of SMEs make it important for a system to be implemented whereby funding can be obtained for various business operations, particularly technical upgrades, promotion, training, and the creation of financial and human capital. The development agency for SMEs, Small and Medium Enterprise Development Authority (SMEDA), is Pakistan's cornerstone organization providing the requisite resources to enable SMEs to address endogenous flaws in nature (Sadiq, 2010).

SMEs are a means of moving forward in developing economies. As research on the significance of SMEs is ongoing, progress on the issues and the growth of Pakistan's SMEs is decelerating. Many SMEs are not approved by government entities and do not have a reference for receiving SMEDA support or assistance (Ali, Azam, Muhammad Naveed, \& Abid, 2020). However, the SMEDA has performed well and progressed during times when the proliferation of SMEs was restrained. Therefore, this study encourages the recognition of the value of SMEs and explores the influential drivers from the stability perspective of SME development in Pakistan.

Though SMEs' growth accomplishments are normal, it is known that entrepreneurs face many hurdles that restrict their success and development. SME growth analysis has found that the frequency of decline is greater in developing economies than in all other industrialized economies (Okpara, 2011). The challenges facing SMEs in Pakistan are related to economic development, which are substantially different from those confronted in developed economies. Overall, the problems hindering the development and survival of SMEs and causing their failure in Pakistan can be divided into five main categories, namely the absence of financial funds, lack of management knowledge, corruption, high interest rates, and decaying infrastructure. These difficulties severely hinder the sustainable growth of SMEs (Jamali, Anka, \& Khooharo, 2010). In Pakistan, the SMEDA operates to promote SMEs but concentrates mainly on upper-income domains, though many Pakistani SMEs are in the lower-income segments. Small Business Finance Corporations (SBFC) are, along with the SMEDA, supporting SMEs in Pakistan to acquire credit financing; however, weak, incomplete, and inconsistent government action and tax regulations are the key hurdles to the development of SMEs (Ali Shah, Mehmood, Aamir Hashmi, Maqsood Shah, \& Muhammad Shaikh, 2011).

A few previous types of research have analytically examined the problems affecting the socioeconomic growth of SMEs in other developing economies, such as Malaysia, Bangladesh, and Indonesia. According to the National Statistics Bureau of China, SMEs represented 99.3\% of all enterprises in China in 2012, and they contributed $60 \%$ of China's GDP (Shannxi, 2016). This statistic indicates the high value of SMEs in both advanced and developing economies. However, SMEs are facing substantial barriers, especially in developing countries. This study seeks to identify the key challenges facing SMEs in Pakistan and analyze the reasons for the barriers to their development. Thus, we can detail a strategy in Pakistan with appropriate insights to achieve quick and stable development of the economy.

The studies on Pakistan, and the impacts of a few characteristics in the overall evaluation of the economic development of Pakistan SMEs, are discussed on an interpersonal basis. Several other articles have studied whether or not significant influencing conditions are acceptable for enterprises (Ali et al., 2020).

This study will demonstrate the importance of highlighting the hindrance factors in Pakistan's SME development. Second, the results of the research will make it more feasible to build a stable environment for policymakers and entrepreneurs and gain support that will encourage the development of SMEs. Third, this is an opportunity for Pakistan's SMEs to procure new awareness of observable evidence.

Interestingly, this study will help SME owners in Pakistan to understand the aspects which are hindering their development. Pakistan's SMEs are critical to the country's economic development, but they do not get the support they need due to limited visibility and the absence of awareness. There is insufficient information on the development of SMEs, and extensive research in this field is still needed. Entrepreneurs need to have in-depth knowledge of the problems hindering the development of Pakistan's SMEs, and this study examines the recognition of measures that influence their survival. Furthermore, recent research examines the consequences of training, several dynamics of business success, and the introduction of stability to the hindering elements that lead to SME failure.

Figure 1 shows the theoretical framework constructed on the basis of evaluating the imperative elements that lead to SME failure in Pakistan. These elements also lead to business development failure and will ultimately reduce the number of SMEs. This research also includes marketing, which is essential to SME promotion at the national and international levels, although the primary focus of this research is to establish and emphasize the factors hindering the development of SMEs in Pakistan. 


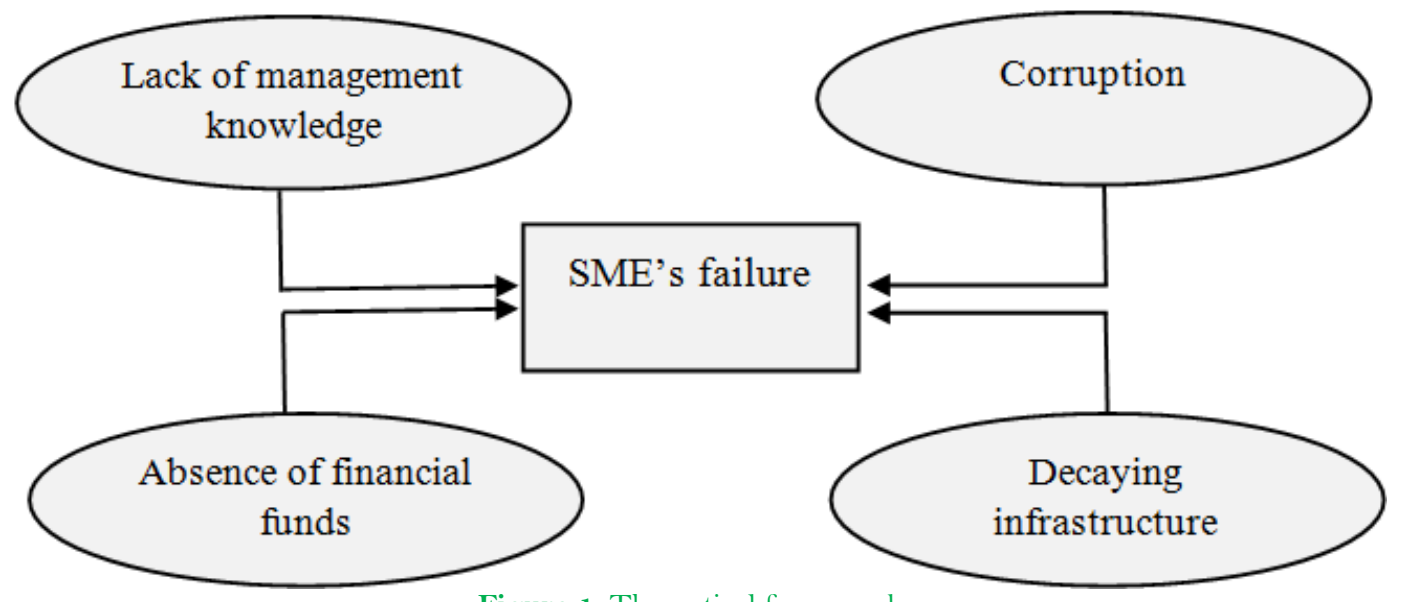

Figure 1. Theoretical framework.

\section{Literature Review}

The literature on obstacles to SME development is comparatively broad (Wang, 2016). A couple of the important articles from the 1990s are studies of Sri Lanka's clothing industry and Tanzania's building and design businesses (Sánchez-Rodríguez, Martínez-Lorente, \& Hemsworth, 2019). Three main barriers were defined by Levy (1993), namely access to financing, access to non-financial resources, and increased costs. Furthermore, he indicated that the principal barrier that financial restrictions created was the difficulty for organizations to expand. A heavy tax restriction was also established as a major barrier for SMEs. The study concentrated on particular sectors to provide more comprehensive and specific insights on the issues facing SMEs. However, the findings could not be widely used due to the lack of revised data and the cost of performing the necessary assessments.

Prior research has also demonstrated that a variety of obstacles, particularly a lack of funding and strategic support, are hampering the development of SME enterprises, but the level at which scarce financial means is a major barrier to corporate development remains uncertain. Results demonstrate that extra funding is frequently not needed to undertake a profitable business operation and that a shortage of capital could be offset by innovation and effort (Dia, 1996; Godsell, 1991; Harper \& Soon, 1979; Hart, 1972). Furthermore, Kallon (1990) indicated that the ratio of funding required to start a company is negatively significant when it comes to the company's rate of expansion. He further stated that having exposure to credit facilities did not, in a meaningful way, lead to successful entrepreneurship, and if it did, the association might be unfavorable.

The challenges concerning the advancement of SMEs within particular areas have been studied by a large number of researchers (AlManei, Salonitis, \& Xu, 2017; Lampadarios, 2016; Paul, Parthasarathy, \& Gupta, 2017), although, as a community, relatively few studies have focused on developing economies such as Pakistan. By studying developing economies as a collective, it is possible to expose certain common challenges. In developing economies, the association among companies' attributes and obstacles to their development is an essential part of the discussion (Wang, 2016), and various forms of businesses ownership as drivers of development are an especially important concern. Wang (2016) further added that private companies grow quicker than state-owned firms, which usually focus their priorities on work development but have a less productive use of resources. However, comparisons between small public and private SMEs are very unusual, and this is likely associated with the success of major large corporations (Saastamoinen, Reijonen, \& Tammi, 2018).

On the contrary, a few other studies have found that local enterprises are being poorly capitalized. To establish and maintain an enterprise, entrepreneurs prefer to rely mostly on their own savings or borrow from their relatives. This source of capital structure is restrictive, and access to anticipated benefits is an obstacle. Kallon (1990) evaluated that, for their primary source of finance, $67.5 \%$ of the enterprises surveyed relied on individual investments, $12.3 \%$ had access to family resources, $8.2 \%$ used financial institutions, and $9.6 \%$ drew funds from associates, stakeholders and other resources. Keyser, de Kruif, \& Frese (2000) highlighted that insufficient financial resources were reported to be the main challenge for entrepreneurs because only $26 \%$ of businesspeople secured sufficient finance to establish their organizations. According to research by Lisbona, Palaci, Salanova, \& Frese (2018), the volume of financial resources was noticed to be positively linked to business performance.

Analysis of the role of resources in SME failure in Pakistan is inconsistent and thus brings uncertainty (Ali et al., 2020). This reinforces the significance of this research; it is important to develop an improved perception of the function of investment throughout the achievement or insolvency of SMEs in Pakistan. As a whole, although they need funding, most small companies do not fulfill the criteria for bank loans, while those who do fulfill the criteria find bank loans extremely costly in terms of the repayment schedule (Gray, Cooley, \& Lutabingwa, 1997).

Management challenges have been considered as significant drivers of enterprise insolvency for SMEs, particularly accounting, financing, training, and management concerns. Inadequate record management and inefficient core management abilities are significant contributors to the insolvency of SMEs in Pakistan. The absence of management knowledge makes it impossible for entrepreneurs to thrive (Naveed, Hongxing, Akhtar, Anwer, \& Alemzero, 2020). Many other reasons impeding the development of SMEs have also been reported, such as ineffective recordkeeping, entrepreneurial immaturity, technological incompetence, poor management skills, lack of preparation, and inadequate marketing analysis (Lussier, 1996; Mahadea, 1997; Van Scheers \& Radipere, 2005). However, many researchers have not established the management issues or difficulties that lead to the failure of SMEs in Pakistan. Identifying the management issues that contribute most to the failure of SMEs will be a crucial step in solving the problem.

Corruption, decaying infrastructure, impoverished regions, inability to perform basic marketing plans, as well as other recognized influences all negatively affect SME development (Tushabomwe-Kazooba, 2006). Corruption, deception and other illegal activities are the biggest challenges for SMEs. In specific developing economies, these practices have significantly hindered business entrepreneurship. These dishonest operations allow those in positions of authority, government, and control to earn profits quickly and illegally. Therefore, corruption, in 
particular, affects individuals in multiple business sectors, especially SMEs. It also compromises the respect and commitment of SMEs to challenge the legal structure, public credibility, and taxation regime (Pope \& International, 2000). Virtually every developing economy has its own variant of corruption with an unquantifiable expense to businesspeople, communities, municipal government, and the social system as a whole. Consequently, from previous studies, the effect of corruption on the growth of SMEs is still uncertain. Therefore, an awareness of the unique effects of corruption on the development of SMEs when designing approaches to resolve the problem is essential.

The research highlighted concerns, such as the absence of financial funds, insufficient management knowledge, corruption, decaying infrastructure, and high interest rates, which lead to SME failure. In Pakistan, the lack of management knowledge and corruption are major barriers to the development of SMEs. Therefore, it is necessary to determine which variables affect the advancement of SMEs. These variables include weak competition for goods and services and the inability to access or buy technologies. One of the key accomplishments of SME ownership is that it enables individuals, particularly those who are unemployed, to join the socioeconomic norms of the community (Harris \& Gibson, 2006). However, to drive the economy's development forward, Pakistan depends on SME stability. In Pakistan, the company loss rate shows that new and inexperienced enterprises are in desperate need of support, and to obtain support, the challenges they encounter need to be recognized.

\subsection{Hypothesis Development}

Previous SME surveys in developing economies have described lack of financial capital, lack of managerial skills, corruption, and inadequate infrastructure as primary barriers to the development of SMEs (Kiggundu, 2002; Okpara \& Wynn, 2007; Tushabomwe-Kazooba, 2006). Although some investigations produced contradictory outcomes, others have demonstrated discrepancies that make further study essential. As a result, the following hypotheses have been formulated to strengthen our awareness of the challenges faced by SMEs in Pakistan:

H1: Lack of management knowledge is negatively linked to SME failure.

H2: Corruption is negatively linked to SME failure.

H3: Decaying infrastructure is negatively linked to SME failure.

H4: Absence of financial funds is negatively linked to SME failure.

\section{Methodology \\ 3.1. Sample Design}

The questionnaire designed for this study was distributed to a random group of 320 owners and staff members of different SMEs in the province of Punjab, Pakistan. The enterprises were selected randomly from SMEDA ${ }^{1}$ and the Federation of Pakistan Chambers of Commerce \& Industry (FPCCI) 2 .

The questionnaires were forwarded by hand to the listed firms' locations, and the data was gathered by hand on a specified pick-up day to encourage a high rate of response. Five educated coordinators and three team assistants were given responsibility for the dissemination and selection of the questionnaire. The delivery was carried out in this manner to avoid local postal system challenges and to respond directly to questions regarding the context and purpose of the study. Out of the 320 questionnaires circulated, 226 were collected, reflecting an answer rate of approximately 70\%. The study took place between April 12 and August 20, 2019.

\subsection{Data Collection Instruments}

Two types of instruments were used to gather statistics, the demographic survey, and the small enterprise questionnaire, which focused on 30 measures related to the main concerns facing SMEs in Pakistan. The questions were expressed with a potential spectrum of reactions using a Likert-type scale, where $1=$ strongly agree and $5=$ strongly disagree.

\subsection{Instrument Validation}

The instruments were proposed to a group consisting of five SME professionals, who were consultants for validation in Pakistan and China. For each of the tools, the professionals were asked to study the items to decide whether these elements were beyond the reading skills and comprehension of Pakistan's SME owners and staff. The instruments were resubmitted to the professionals for further examination after several small changes and improvements were made. For the analysis, the professionals suggested using modified tools, and Cronbach's $\alpha$ was 0.82 .

\section{Research Findings \\ 4.1. Factor Analysis}

A factor analysis reviewing the survival aspects of SMEs in Pakistan was undertaken to assess if there was a resolved collection of difficulties or causes. Each object had a minimum factor loading of 0.50 , and $54.55 \%$ of the variation was clarified by four variables (lack of management knowledge, corruption, decaying infrastructure, absence of financial funds), as shown in Table 1 . The variable reliabilities are $0.88,0.85,0.84$, and 0.86 , respectively.

\subsection{Descriptive Analysis and Correlation Matrix}

Table 2 contains the descriptive statistics and correlations for the study variables proposed in this research. The mean and standard deviation $(\mathrm{SD})$ results are as follows: $\mathrm{LMK}($ mean $=4.32, \mathrm{SD}=0.61)$, Corruption $($ mean $=$ $4.59, \mathrm{SD}=0.52)$, DI $($ mean $=4.31, \mathrm{SD}=0.61)$, and AFF $($ mean $=4.76, \mathrm{SD}=0.79)$. The table shows the outcomes of the correlation between the study variables and SME performance.

\footnotetext{
${ }^{1}$ https://smeda.org/index.php?option=com_phocadownload\&view=category\&id=44: punjab-clusterprofiles\&Itemid=742

2 http://www.pastic.gov.pk/database_chamber_of_comm.aspx
} 
Table 1. Item description and factor analysis.

\begin{tabular}{|c|c|}
\hline Description & Factor loading \\
\hline \multicolumn{2}{|l|}{ Lack of management knowledge (LMK) $(\alpha=0.88)$} \\
\hline Deficiency of management knowledge & 0.87 \\
\hline Deficiency of knowledge in SME management & 0.85 \\
\hline Deficiency of training in enterprise management & 0.81 \\
\hline Deficiency of training in financial planning & 0.83 \\
\hline Deficiency of training in the marketing department & 0.88 \\
\hline Deficiency of training in accounts & 0.84 \\
\hline Deficiency of training in HR management & 0.82 \\
\hline Lack of specialist staff & 0.78 \\
\hline Deficiency in mentoring employees & 0.68 \\
\hline Variance & 28 \\
\hline \multicolumn{2}{|l|}{ Corruption $(\alpha=0.85)$} \\
\hline Value squeezing & 0.86 \\
\hline Illegal ways of covering corruption & 0.82 \\
\hline Availing of the government contract against money & 0.85 \\
\hline Using other means of sources for corruption & 0.87 \\
\hline Offering money to acquire a loan & 0.67 \\
\hline Providing extra interest on a loan & 0.77 \\
\hline Solving business matters with money & 0.87 \\
\hline Offering money is normal in firms & 0.88 \\
\hline Variance & 24 \\
\hline \multicolumn{2}{|l|}{ Decaying infrastructure (DI) $(\alpha=0.84)$} \\
\hline Bad state of roads & 0.86 \\
\hline Slow means of communication & 0.82 \\
\hline Unreliable power source & 0.76 \\
\hline Harbor mobbing means & 0.78 \\
\hline Overcrowding of bridges and roads & 0.81 \\
\hline Variance & 23 \\
\hline \multicolumn{2}{|l|}{ Absence of financial funds (AFF) $(\alpha=0.86)$} \\
\hline Insufficient financial sources & 0.84 \\
\hline Insufficient financial funding & 0.83 \\
\hline Difficulty in receiving loans & 0.87 \\
\hline Deficiency in financial regulations & 0.85 \\
\hline Variance & 25 \\
\hline
\end{tabular}

Table 2. Descriptive statistics and correlation analysis.

\begin{tabular}{l|c|c|c|c|c|c|c|c|c|c|c}
\hline Variable & Mean & SD & $\mathbf{1}$ & $\mathbf{2}$ & $\mathbf{3}$ & $\mathbf{4}$ & $\mathbf{5}$ & $\mathbf{6}$ & $\mathbf{7}$ & $\mathbf{8}$ & $\mathbf{9}$ \\
\hline Gender & 1.59 & 0.98 & - & & & & & & & & \\
\hline Age & 39.02 & 5.25 & 0.16 & - & & & & & & & \\
\hline Qualification & 15.76 & 6.34 & 0.15 & 0.13 & - & & & & & & \\
\hline Experience & 7.49 & 0.94 & 0.30 & 0.11 & 0.20 & - & & & & & \\
\hline LMK & 4.32 & 0.61 & 0.23 & 0.13 & 0.40 & -0.35 & - & & & & \\
\hline Corruption & 4.59 & 0.52 & 0.16 & 0.11 & 0.20 & -0.29 & -0.70 & - & & & \\
\hline DI & 4.31 & 0.61 & 0.20 & 0.13 & 0.08 & -0.25 & -0.65 & 0.59 & - & & \\
\hline AFF & 4.76 & 0.79 & 0.26 & 0.18 & 0.12 & -0.33 & -0.59 & 0.63 & -0.57 & - & \\
\hline SME performance & 3.23 & 0.52 & 0.11 & 0.23 & 0.25 & -0.28 & -0.65 & 0.62 & -0.49 & -0.62 & - \\
\hline
\end{tabular}

The results indicate that there is a clear negative relationship between SME performance and LMK, corruption and AFF. These relationships support $\mathrm{H}_{1}, \mathrm{H}_{2}$ and $\mathrm{H}_{4}$. The results are also compatible with previous research that showed that these variables have a negative effect on the growth of small businesses (Keyser et al., 2000; Lussier, 1996; Mahadea, 1997; Mambula, 2002; Monkhouse, 1995; Okpara, 2011; Tushabomwe-Kazooba, 2006). It's worth noting that corruption and decaying infrastructure are not as significant to SME staff as the absence of financial funds, inadequate education, and lack of management knowledge.

\subsection{Multiple Regression Analysis}

Table 3 shows the outcomes of the multiple regression of the research variables by analyzing the incremental effects of LMK, corruption, DI and AFF, and all significantly lead to SME failure. These results support H3. Also, $\mathrm{R}^{2}=68$, which indicates a $68 \%$ variance in SMEs due to LMK, corruption, DI and AFF.

\begin{tabular}{l|c|c|c}
\multicolumn{4}{c}{ Table 3. Multiple regression variables. } \\
\hline Variable & $\boldsymbol{\beta}$ & $\mathbf{R}$ & P-value \\
\hline LMK & 0.65 & 0.53 & $0.000^{*}$ \\
\hline Corruption & 0.71 & 0.66 & $0.002^{*}$ \\
\hline DI & 0.69 & 0.67 & $0.004^{* *}$ \\
\hline AFF & 0.55 & 0.67 & $0.000^{*}$ \\
\hline Note: ${ }^{*} \mathrm{p}<0.05 ;{ }^{* *} \mathrm{p}<0.01, \mathrm{R}^{2}=68$.
\end{tabular}

\subsection{Results and Discussion}

This research contributes to our knowledge about the influences that restrict the development of Pakistan's SMEs by focusing on the four most significant results - lack of management knowledge, corruption, decaying 
infrastructure, and the absence of financial funds. All were found to be negatively correlated to SME failure, and this is supported by previous research (Keyser et al., 2000; Lussier, 1996; Mahadea, 1997; Mambula, 2002; Monkhouse, 1995; Okpara, 2011; Tushabomwe-Kazooba, 2006).

The findings demonstrate the effects of the absence of financial funds brought on by the failure to collect money and the inability to obtain funding from financial institutions. The challenge of borrowing money from the bank is difficult due to the lack of necessary guarantees of fund loans, and it is one of the key factors identified for the lack of financial funds. These results are also in line with those of Okpara \& Wynn (2007). Outcomes indicate that corruption negatively correlates with SMEs. There are also discouraging concerns around SME corruption and its effect on enterprises. However, if SMEDA arranged seminars on the awareness of SME stability and development, this would help to reduce some of the negative issues.

Lack of management knowledge is another barrier to the advancement of SMEs in Pakistan. According to the results, the majority of owners do not have sufficient information regarding business operation or staff training. Consequently, insufficient training and lack of expertise in management skills have detrimental implications and significantly contribute to the failure of SMEs. However, operating enterprises in rural communities that are not easily accessible can be troublesome, even though rural communities may have a strong market for their goods. In terms of business sustainability, this reduces the willingness of SMEs to grow and, in turn, earn a profit.

\subsection{SME Stability}

Regardless of all the proposed outcomes, the stability of SMEs is essential for growth and development. Many types of research have found that SME stability is the key to boosting the economic level of any country via employment and income, and developing countries need to take serious steps to reduce or eliminate the challenges that have been identified. As previously explained, the main constraints for SMEs in Pakistan need to be addressed urgently to create SME stability. Therefore, it is suggested that initiatives aimed at encouraging, helping, and promoting SMEs would lead to economic development and stability, thus improving SME success and performance.

\section{Conclusion and Future Research}

SMEs are advancement drivers for developing countries such as Pakistan, and they provide substantial support for employment, which assists in easing poverty. Built on the outcomes of this research, numerous aspects were recognized as liable for hindering SME development and survival in Pakistan. Overall, these are a lack of management knowledge, corruption, a decaying infrastructure, and an absence of financial funds. Insufficient funds and the difficulties of securing finance from monetary associations and federal organizations were also highlighted as the main aspects hindering SME development. The unfavorable policy structure discourages entrepreneurs from seeking capital for start-up or for the expansion of current operations. Additionally, a serious communication flaw has been recognized among confined enterprise services benefactors regarding funding.

The inadequacy of existing management knowledge and skills is a major constraint for SMEs. The enterprise owners and staff who took part in this study stated that they had very little or no management knowledge or experience before opening their enterprises. They specified this lack of essential enterprise management knowledge as a significant hindrance in relation to development and survival. Decaying infrastructure is an additional barrier to SME growth. Important infrastructure and facilities, such as roads, highways, electricity, and other telecommunication arrangements that might facilitate success for SMEs, are not sufficiently available.

Corruption is also a huge constraint to SME survival and development in Pakistan. The majority of owners and staff stated that the procedure of obtaining support from the federal government is not just difficult but also relies on bribery and political links.

To build on what we have studied in this research, the focus could be enhanced to include the capture of additional problem regions in the literature. Also, future research should include a larger sample geographically.

\subsection{Recommendations}

The findings of this study demonstrate that a variety of reasons are responsible for hindering the development of SMEs in Pakistan. SME owners are advised to obtain cheap loans, get low-interest loans from financial institutions, borrow from friends and family, arrange advance consumer payments, or obtain loans from micro institutions. It is also suggested that the government should take the requisite steps at local, state, and federal levels to begin improving and sustaining Pakistan's current infrastructure.

\section{References}

Ali, S., Azam, F., Muhammad Naveed, H., \& Abid, W. (2020). Impact of prestigious indicators on sustainable growth of small and mediumsized enterprises in Pakistan. Asian Journal of Economics and Empirical Research, 7(2), 251-257.Available at: https://doi.org/10.20448/journal.501.2020.72.251.257.

Ali Shah, A., Mehmood, T., Aamir Hashmi, M., Maqsood Shah, S., \& Muhammad Shaikh, F. (2011). Performance of SMEs in export growth and Its impact on economy of Pakistan. International Journal of Business and Management, 6(7), 287.Available at: https://doi.org/10.5539/ijbm.v6n7p287.

AlManei, M., Salonitis, K., \& Xu, Y. (2017). Lean implementation frameworks: The challenges for SMEs. Procedia Cirp, 63, 750755.Available at: 10.1016/j.procir.2017.03.170.

Dia, M. (1996). Africa's management in the 1990s and beyond: Reconciling indigenous and transplanted institutions. The Journal of Modern African Studies, 35(4), 745-778.Available at: https://doi.org/10.1596/0-82 13-3431-X.

Godsell, G. (1991). Entrepreneurs embattled: Barriers to entrepreneurship in South Africa. The Culture of Entrepreneurship (pp. 85-97). San Francisco, CA: ICS Press.

Gray, K. R., Cooley, W., \& Lutabingwa, J. (1997). Small-scale manufacturing in Kenya. Journal of Small Business Management, $35(1)$, 66-72.

Harper, M., \& Soon, T. T. (1979). Small enterprises in developing countriescase studies and conclusions (pp. 115). Guildford, London: Intermediate Technology.

Harris, M. L., \& Gibson, S. G. (2006). Determining the common problems of early growth small businesses in Eastern North Carolina. Quarterly Journal. S.A.M.Advanced Management Journal, $71(2), 39-45$.

Hart, G. P. (1972). Some socioeconomic aspects of African entrepreneurship. PhD Thesis. Rhodes University Grahams Town. 
Jamali, S. K., Anka, D. L. M., \& Khooharo, A. A. (2010). An evaluation of small and medium enterprises development in Pakistan. OIDA International Journal of Sustainable Development, 2(1), 43-50.

Kallon, K. M. (1990). The economics of sierra leonean entrepreneurship. University Press of Amer. Retrieved from: https://rowman.com/ISBN/9780819175274/The-Economics-of-Sierra-Leonean-Entrepreneurship.

Keyser, M., de Kruif, M., \& Frese, M. (2000). The psychological strategy process and sociodemographic variables as predictors of success for micro- and small-scale business owners in Zambia. In M. Frese (Ed.), Success and failure of microbusiness owners in Africa: A psychological approach (pp. 31-53). Quorum Books/Greenwood Publishing Group.

Kiggundu, M. N. (2002). Entrepreneurs and entrepreneurship in Africa: What is known and what needs to be done. Journal of Developmental Entrepreneurship, 7(3), 239-258.

Lampadarios, E. (2016). Critical challenges for SMEs in the UK chemical distribution industry. Journal of Business Chemistry, 13(1), 17-32.

Levy, B. (1993). Obstacles to developing indigenous small and medium enterprises: An empirical assessment. The World Bank Economic Review, 7(1), 65-83.

Lisbona, A., Palaci, F., Salanova, M., \& Frese, M. (2018). The effects of work engagement and self-efficacy on personal initiative and performance. Psicothema, 30, 89-96.Available at: 10.7334/psicothema2016.245.

Lussier, R. N. (1996). Reasons why small businesses fail: And how to avoid failure. The Entrepreneurial Executive, 1(2), 10-17.

Mahadea, D. (1997). Financial constraints on small business entrepreneurs: A Transkei case study. Acta Academica-University of the Orange Free State, 29, 70-89.

Mambula, C. (2002). Perceptions of SME growth constraints in Nigeria. Journal of Small Business Management, 4O(1), 58-65.Available at: https://doi.org/10.1111/1540-627x.00039

Monkhouse, E. (1995). The role of competitive benchmarking in small-to medium-sized enterprises. Benchmarking for Quality Management \&® Technology, 2(4), 41-50.Available at: https://doi.org/10.1 108/14635779510102847.

Naveed, H. M., Hongxing, Y., Akhtar, M., Anwer, M. U., \& Alemzero, D. (2020). The impact of customer feedback on organizational health when employee empowerment works as a moderator: Evidence from Pakistani Fast Food Industry. Business and Economic Research, $10(3)$, 65.Available at: https://doi.org/10.5296/ber.v10i3.17372.

Okpara, J. O. (2011). Factors constraining the growth and survival of SMEs in Nigeria: Implications for poverty alleviation. Management Research Review, 34(2), 156-171.Available at: https://doi.org/10.1108/01409171111102786.

Okpara, J. O., \& Wynn, P. (2007). Determinants of small business growth constraints in a sub-Saharan African economy. SAM Advanced Management Journal, 72(2), 24-35.

Paul, J., Parthasarathy, S., \& Gupta, P. (2017). Exporting challenges of SMEs: A review and future research agenda. Journal of World Business, $52(3), 327-342$.

Pope, J., \& International, T. (2000). TI Source Book 2000: Confronting corruption: The elements of a national integrity system. Berlin: Transparency International (TI).

Saastamoinen, J., Reijonen, H., \& Tammi, T. (2018). Should SMEs pursue public procurement to improve innovative performance? Technovation, 69(2018), 2-14.Available at: https://doi.org/10.1016/j.technovation.2017.10.003.

Sadiq, M. (2010). Determinants of Poverty in Pakistan. Hamburg Review of Social Sciences, 4(2010), $193-213$.

Saeed, K. A. (2013). The economy of Pakistan (3th ed.): Oxford Univ. Press.

Sánchez-Rodríguez, C., Martínez-Lorente, A. R., \& Hemsworth, D. (2019). E-procurement in small and medium sized enterprises; facilitators, obstacles and effect on performance. Benchmarking: An International Journal, 27(2), 839-866.Available at: https://doi.org/10.1108/BIJ-12-2018-0413.

Shannxi, P. (2016). Incubators, SMEs, and economic development of China. International Journal of Multimedia and Ubiquitous Engineering, 11(1), 311-318.Available at: https://doi.org/10.14257/ijmue.2016.11.1.29

Syed, A., Ahmadani, M. M., Shaikh, N., \& Shaikh, F. M. (2012). Impact analysis of SMEs sector in economic development of Pakistan: A case of Sindh. Journal of Asian Business Strategy, 2(2), 44-53.

Tushabomwe-Kazooba, C. (2006). Causes of small business failure in Uganda: A case study from Bushenyi and Mbarara towns. 8, 27-35.

Van Scheers, L., \& Radipere, S. (2005). Perceptions of small business owners on managerial skills: Problems in business development in South Africa. World Review of Science, Technology and Sustainable Development, 2(3-4), 336-351.Available at: https://doi.org/10.1504/wrstsd.2005.007692.

Wang, Y. (2016). What are the biggest obstacles to growth of SMEs in developing countries?-An empirical evidence from an enterprise survey. Borsa Istanbul Review, 16(3), 167-176.Available at: https://doi.org/10.1016/j.bir.2016.06.001. 